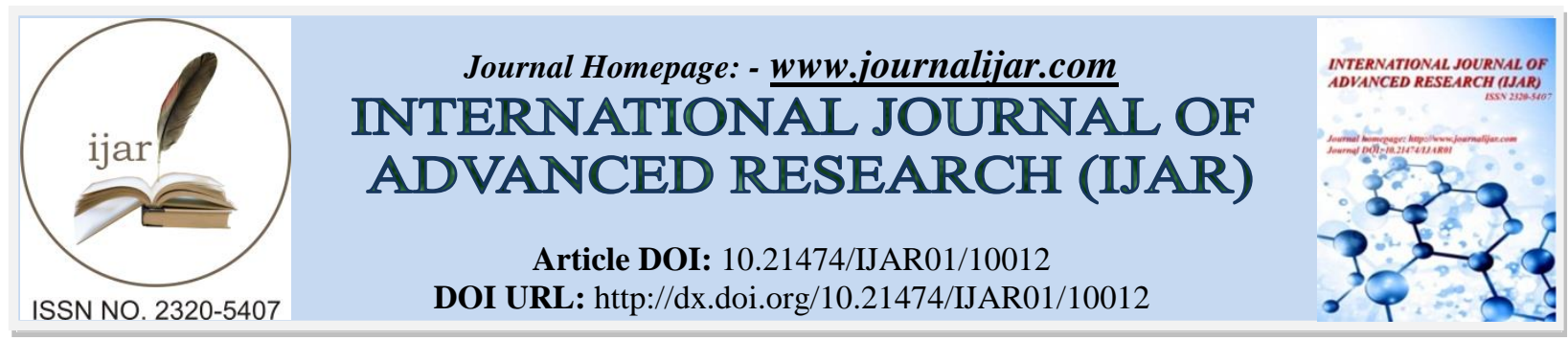

RESEARCH ARTICLE

\title{
ALLEVIATION OF IMPACTS OF SALT STRESS ON THE GROWTH PARAMETERS OF GROUNDNUT (ARACHIS HYPOGAEA L.) EMPLOYING HALOTOLERANT PGPR.
}

Shweta Bhatt ${ }^{1}$, Dr.Ragini Raghav ${ }^{1}$ and Dr. Neepa Pandhi ${ }^{2}$.

1. Department of Biotechnology, Shree M. \& N. Virani Science College, Rajkot 360005, Gujarat, India.

2. Department of Microbiology, Shree M. \& N. Virani Science College, Rajkot 360005, Gujarat, India.

\section{Manuscript Info}

Manuscript History

Received: 08 September 2019

Final Accepted: 10 October 2019

Published: November 2019

Key words:-

Groundnut; salinity; PGPR; PGP traits; plant growth.

\section{Abstract}

Bacteria surrounding plant roots and providing a stimulatory effect to the plants are termed Plant growth promoting rhizobacteria (PGPR). They are highly beneficial microorganisms which can be utilized to enhance plant responses against biotic and abiotic stresses. The present study involves the isolation of thirty five isolates from the rhizosphere of groundnut plants from Jodia (or Jodiya) Gujarat. The isolates were screened for salinity tolerance and observed that all were able to grow upto $6 \% \mathrm{NaCl}$ and twenty two isolates had shown growth upto $12 \%$ $\mathrm{NaCl}$ concentration. All the isolates were further screened for Plant growth promoting traits out of which PGPR J9 exhibited all traits including hydrogen cyanide, ammonia, siderophore, chitinase, indole acetic acid production, phosphate solubilization and nitrogen fixation positive. The isolate $\mathrm{J} 9$ was further used for pot experiment and showed augmentation in growth of physical parameters (shoot length, root length, dry weight, wet weight, number of leaves, number of stems, leaf area) of plant under salt stress and without salt stress (100mM) with reference to controls. Thus this isolate may reduce the use of chemical fertilizer and give input in enhancing the growth of plant in salt stress.

Copy Right, IJAR, 2019,. All rights reserved.

\section{Introduction:-}

In the present era, the crop production has been affected by global climate change leads to various environmental stresses such as salinity, rainfall, drought, extreme temperatures and floods (Ilangumaran and Smith, 2017). These pose a threat to agricultural sustainability with increasing global population, higher food demand and security and depletion of availability of cultivatable lands. Amongst the environmental stresses, the soil salinity majorly contributes in reduction and deterioration of cultivatable land areas which hampers crop productivity and its quality (Yamaguchi and Blumwald, 2005, Shahbaz and Ashraf, 2013). Globally, nearly more than 800 million hectares (ha) of area is known to be salinity affected (i.e. $6 \%$ of total land mass on the earth). It is estimated that with a rate of increase of $10 \%$ annually, by year 2050 half of the agricultural land will be entrapped with high salinity.

The Indian peninsula has a coastline of $7517 \mathrm{~km}$ of which the state of Gujarat has the longest coastal line of 1600 km (Garg, 2012). The Kutch and Saurashtra regions of Gujarat covers about $1125 \mathrm{~km}$. Approximately $1 \mathrm{~km}$ distance from coastline is yearly affected with elevated salinity due to mixing of ground water and oceanic saline water. Till date approximately, 5 to $7.5 \mathrm{~km}$ wide strip of the inland area has become engrossed with salinity.

Corresponding Author:-Shweta Bhatt.

Address:-Department of Biotechnology, Shree M. \& N. Virani Science College, Rajkot 360005, Gujarat, India. 
Salinity is an abiotic stress, which affects the growth of crops by interfering with available nutrients uptake and mineral transport (Grattan and Grieve, 1992). Plant under stress activates several signaling pathways by producing stress tolerance hormones, poly amines production, activation and synthesis of antioxidant enzymes, and production of osmoprotectant (Groß et al., 2013) which helps in survivability of plant cells (Martínez-Atienza et al., 2007). The arid and semi-arid regions of Gujarat state are major producer of, groundnut crops (Arachis hypogaea L). However, due to increase in soil salinity the production of groundnut has decreased severely over the years. To overcome the problem, commercial chemical fertilizers have been employed for nourishment of soil to improve production of the groundnut. However, excessive use of fertilizers aids in environmental pollution through heavy metal and nitrates accumulation and water eutrophication etc (Savci, 2012).

Plant growth promoting rhizobacteria (PGPR) are bacteria that colonize roots of the plants and facilitates in stress tolerance in plants through various parameters such as antioxidants, gibberellins, indole acetic acid, phosphate solubilization, chitiniase and siderophore production etc. Halotolerant PGPR facilitates plant growth in salinity stress and have a potential to be used to enhance plant growth under salinity stress. In the present study, the rhizospheric microorganisms were isolated and screened for their plant growth promoting traits. The selected strain was further employed for its ability to promote and facilitate growth of the groundnut plants under saline stress.

\section{Material and Methods:-}

\section{Sample Collection and Isolation of Rhizobacteria}

The soil samples were collected from the groundnut crop field of the Jodia or Jodiya (J), Jamnagar district from the state of Gujarat. The groundnut plants were uprooted from the soil and the soil surrounding and attach to the roots was put in autoclaved bags and brought to the laboratory. The soil samples were serial diluted upto $10^{-8}$ and spreading was performed on agar plates. The bacteria with distinct colony morphology were selected and again sub cultured to get purified isolates

\section{Characterization of the Soil Sample}

The various physicochemical parameters were quantified including; electrical conductivity (EC), $\mathrm{pH}$, available nitrogen $(\mathrm{mg} / \mathrm{kg})$, phosphorus $(\mathrm{mg} / \mathrm{kg})$, magnesium $(\mathrm{mg} / \mathrm{kg})$ potassium $(\mathrm{mg} / \mathrm{kg})$, sulphate $(\mathrm{mg} / \mathrm{g})$, total organic carbon $(\%)$, chloride $(\mathrm{mg} / \mathrm{kg})$, sodium $(\mathrm{mg} / \mathrm{kg})$, calcium $(\mathrm{mg} / \mathrm{kg})$, etc. of the rhizospheric soil sample.

\section{Salt Tolerance Ability}

The salt tolerance ability of the isolates was conducted by growing the microorganisms on nutrient agar (NA) medium containing different concentrations of sodium chloride $(\mathrm{NaCl})$ ranging from $0-12 \%(\mathrm{w} / \mathrm{v})$. The nutrient agar plates were incubated for $48-72$ hours at $37^{\circ} \mathrm{C}$.

All the biochemical and pot experiments were performed in triplicates and standard error was calculated for each parameter. The PGP traits were analyzed with $2 \% \mathrm{NaCl}$ concentration.

\section{Screening of Salt Tolerant Rhizobacteria for PGP Traits}

\section{Phosphate Solubilization}

The phosphate solubilization potential of the isolates was analyzed using Pikovskaya's agar plates (PVK) (Pikovskaya, 1948). The phosphate solubilizing index (PSI) was calculated by the below formula:

$$
\text { PSI }=\frac{\text { Colony diameter }(\text { in } \mathrm{mm})+\text { Halo zone diameter }(\text { in } \mathrm{mm})}{\text { Colony diameter }(\text { in } \mathrm{mm})}
$$

\section{Indole-3-AceticAcid (IAA)}

IAA production by various isolates was quantified using Salkowski's reagent (Gordon and Weber, 1951).

\section{Siderophore production}

Bacterial isolates were assayed for siderophore production on the Chrome azurol S agar medium (Sigma, Ltd.) described by Schwyn and Neilands (Schwyn and Neilands, 1987). Chrome azurol S agar plates were inoculated with the isolates and incubated at $37^{\circ} \mathrm{C}$ for $48-72$ hours. The presence of the yellow-orange halo zone around the isolates was considered as positive result. 


\section{Hydrogen Cyanide production}

HCN production was qualitatively determined by the color change of filter paper(Alström and Burns, 1989).

\section{Ammonia Production}

The qualitative analysis of ammonia was performed as described by Cappuccino et. al. (Cappuccino and Sherman, 1996). The fresh overnight grown bacterial cultures were inoculated in $10 \mathrm{ml}$ peptone broth in test tubes and incubated at $37 \pm 2{ }^{\circ} \mathrm{C}$ for 48 hours. Further after incubation, $0.5 \mathrm{ml}$ of Nessler's reagent was added in the tubes. The yellowish-brown color shows the presence of ammonia.

\section{Chitinase Assay}

Colloidal chitin was prepared and test as performed according to modified method described by Mathivanan, 2014. (Mathivanan et al., 2014).

\section{Identification of the isolate}

Based on the PGP trait's results, it was observed that the isolate J9 exhibited all traits positive and was selected for further studies. The selected isolate J9 was examined morphologically, colony as well as by biochemical methods. The biochemical tests performed were motility test, anaerobic growth, Vogus Proskauer test, acid and gas production from various sugar like glucose, mannitol, maltose, sucrose, fructose, endospore formation, starch hydrolysis, casein hydrolysis, citrate utilization, according to Bergey's Manual of Systemic Bacteriology (Sneath et al., 1986). The molecular identification of J9 was performed by SLS Labs, Surat, Gujarat.

\section{Pot Experiment}

The soil for the pot experiment was obtained from the nearby field around Rajkot. Groundnut seeds were obtained from the local market of Rajkot, Gujarat. The seeds were surface sterilized with $70 \%$ ethanol for 1 min and then kept in $1 \%$ sodium hypochlorite for $3 \mathrm{~min}$ followed by rinsing was done 4 times with sterilized distilled water. For the germination process, $1 \mathrm{ml}$ of 24 hour old bacterial culture $10^{9} \mathrm{CFU} / \mathrm{ml}$ was added on seeds and kept on moist filter paper sheets in the petri dish. The petri dish was covered with other sterilized filter paper sheets and seeds were allowed for germination. The control seeds were without bacterial culture. This was incubated for five days (Piromyou et al., 2011). The non-germinated seeds were removed and the germinated seeds were selected for the pot experiment. For pot trials, the seedlings were sown in plastic polythene pots and were filled with $3 \mathrm{~kg}$ autoclaved soil. The experiment was conducted as follows: ( 3 pots per treatment; 4 seed per pot). The treatments was done in this manner: control -no salt, (Control-Salt), presence of salt (Control+Salt), PGPR D3 with no salt (D3-Salt) and PGPR D3 with salt (D3+Salt). All the work was done in the growth Chamber. The plants were kept and grown in the growth chamber at $25 \pm 2{ }^{\circ} \mathrm{C}$ and $16-\mathrm{h} / 8$-h light/dark cycle. $1 \mathrm{ml}$ of 24 hour old bacterial culture $10^{9} \mathrm{CFU} / \mathrm{ml}$ was applied directly to the base of the seedling after 2 days of plantation. Pots were watered with distilled water daily for seven days after plantation. After that saline water was used to induce stress $(100 \mathrm{mM} \mathrm{NaCl})$ to maintain salinity in the soil till plant harvesting (30 days). Non-saline plants were irrigated only with water.

\section{Growth Parameters}

The plants were harvested after thirty days and studied for physical growth parameters: root height $(\mathrm{cm})$, shoot height $(\mathrm{cm})$, fresh weight, and dry weight. (Bharti et al., 2016).

The plant was washed to remove soil and then the length of shoot, root length was measured. Fresh weight was measured followed by their dry weight measurement after drying at $70{ }^{\circ} \mathrm{C}$ for 3 days.

\section{Result:-}

\section{Isolation of Rhizobacteria and Characterization of the Soil Sample}

The total thirty five isolates J1-J35 were isolated from the rhizosphere of the groundnut plant. The physicochemical analysis of the soil was performed and the results showed that the soil has medium fertility (Table 1).

\section{Salt Tolerance Ability}

All the thirty five isolates were screened for their salt tolerating ability at different concentrations of sodium chloride $(2-12 \% \mathrm{w} / \mathrm{v})$. All thirty five isolates from groundnut plants showed healthy growth from $2-6 \% \mathrm{NaCl}(\mathrm{w} / \mathrm{v})$. Jodia isolates J1, J2, J5, J6, J7, J9, J10, J12, J14, J15, J16, J17, J18, J19, J20, J21, J22, J23, J31, J32, J34, J35 showed growth even upto $12 \%$ salt concentrations. 


\section{Screening of Salt Tolerant Rhizobacteria for PGP Traits}

All the traits were performed at $2 \% \mathrm{NaCl}$. Out of thirty five isolates from groundnut plant, J1-17, J21, J25- J35 displayed the nitrogen fixation. The ammonia and hydrogen cyanide production was exhibited by $\mathrm{J} 1,3,5,9,12,13$; J16-J29; J32-J35. In our study the isolates which exhibited positive results for phosphate solubilization index were $\mathrm{J} 1$, J2, J4-10; J15; J17-24; J28, 30, 33. The highest production was exhibited by $\mathrm{J} 21$ in the form of zone of hydrolysis on the petri-plate. The chitinase production was evaluated on plate and calculated as CZ/CS ratio and six isolates $\mathrm{J} 3,9,20,30,33,35$ exhibited positive result in the range from $0.25-1.66$. The IAA production was displayed positive by thirty four isolates $\mathrm{J} 1-28, \mathrm{~J} 30-35$ ranging from $3.6-58.5 \mu \mathrm{g} / \mathrm{ml}$. The isolate $\mathrm{J} 31$ displayed highest IAA production of $58.5 \mu \mathrm{g} / \mathrm{ml}$. In this study, the siderophore production was exhibited by $\mathrm{J} 1,9,14,18,24,28$ isolates on plate (fig. 1).

\section{Identification of isolates}

Gram staining was done of the isolate and was identified as gram positive bacteria. Table 2 shows various morphological and colony characterization of the isolates.

Further the biochemical characterization of the $\mathrm{J} 9$ was performed. The biochemical test explained that the $\mathrm{J} 9$ showed a negative test for motility and positive for VP and citrate. The acid production by various sugars was done qualitatively in which glucose, mannitol and sucrose gave positive results, while maltose and fructose exhibited negative results. The isolate gave a positive result for endospore formation. In the enzymatic analysis, J9 gave casein hydrolysis positive and negative for catalase and starch hydrolysis. The sequence analysis of the 16SrRNA gene of J9 revealed that it shares $100 \%$ identity with Bacillus safensis strain NBRC 100820.

\section{Pot Experiment}

The electrical conductivity (E.C) of the soil was $1.3 \mathrm{mS} / \mathrm{cm}$ and $\mathrm{pH}$ of the soil was 8 . Further the chemical characterization of the soil was as follows: nitrogen, phosphorous and potassium were obtained to be $0.056 \%, 19.1$ $\mathrm{kg} . \mathrm{ha}^{-1}$, and $167.5 \mathrm{mg} \cdot \mathrm{kg}^{-1}$ respectively. The following physical parameters indicate the increase in plant growth in the presence of PGPR J9 under non-saline and saline conditions (fig. 2). The shoot length of the plants showed enhancement of $24 \%$ without salt and $12 \%$ with salinity stress $(100 \mathrm{mM})$ with PGPR J9. The root length was observed to be augmented by $17 \%$ without no salt stress and with salt stress $(100 \mathrm{mM})$ with PGPR J9. Fresh weight was also enhanced by $16 \%$ with salt stress $(100 \mathrm{mM})$ with PGPR J9. Similarly the $22 \%$ increase in dry weight and $12.5 \%$ increase in leaf area were observed under saline conditions using PGPR J9 (fig. 2).

\section{Discussion:-}

Out of all the thirty five isolates (J1 -J35), twenty two isolates exhibited salt tolerance up to $12 \%$ salt. The isolates were screened for PGP traits and observed that the nitrogen fixation ability was shown by twenty eight isolate which is an important parameter for the pant growth. Twenty isolates exhibited positive results for phosphate solubilization. The potency of PGPR for solubilizing the insoluble $\mathrm{P}$ and convert it into a plant acceptable form is an important characteristic for the plant growth (Bar-Yosef et al., 1999). The chitinase production was exhibited by 6 isolates. The thirty four isolates of Jodia showed IAA production. Majeed et. al. in 2015 stated that the bacterial isolates producing IAA shows their potential to utilize as growth hormones and regulators by the plant (Majeed et al., 2015). Six isolates exhibit positive result for siderophore production out of thirty five isolates which is an important chemical for solubilize and sequester iron Fe (III) in the soil and make it available to the plant (Pahari and Mishra, 2017). The pot experiment using groundnut seeds clearly showed that there is enhancement of physical parameters of plant under control environment conditions using PGPR J9. The J9 isolate has augment the shoot length, root length, dry weight, fresh weight, number of leaves and stems of the plant under saline and non-saline conditions. Thus this PGPR J9 has the potential to be use as bio-fertilizer under salinity stress and may replace chemical fertilizers.

\section{Conflict of Interest:}

We declare no conflict of interest

\section{Acknowledgment:-}

The authors are grateful to Department of Biotechnology, Shree M. \& N. Virani Science College, Rajkot, Gujarat. We are thankful to Dr. Shivani Patel, Head Department of Biotechnology, for her support and guidance. 
Table 1:-Assessment of Physicochemical properties of soil sample collected from the rhizosphere of the groundnut plant from Jodia (Tests were performed at Gujarat Institute of Desert Ecology, Bhuj (Kachchh) Gujarat, India).

\begin{tabular}{|c|l|l|}
\hline S.No. & Physicochemical Parameters & $\begin{array}{l}\text { Jodia, } \\
\text { Dist: Jamnagar }\end{array}$ \\
\hline 1. & Soil Type & Shallow, medium black \\
\hline 2. & Salinity EC $(\mathrm{mS} / \mathrm{cm})$ & 2.7 \\
\hline 3. & $\mathrm{pH}$ & 8 \\
\hline 4. & Available Nitrogen $(\mathrm{mg} / \mathrm{kg})$ & 62.7 \\
\hline 5. & Available Phosphorus $(\mathrm{mg} / \mathrm{kg})$ & 13.9 \\
\hline 6. & Potassium $(\mathrm{mg} / \mathrm{kg})$ & 1340 \\
\hline 7. & Total organic carbon $(\%)$ & 0.225 \\
\hline 8. & Chloride $(\mathrm{mg} / \mathrm{kg})$ & 1006.7 \\
\hline 9. & Sulphate $(\mathrm{mg} / \mathrm{g})$ & 1.672 \\
\hline 10. & Sodium $(\mathrm{mg} / \mathrm{kg})$ & 301 \\
\hline 11. & Calcium $(\mathrm{mg} / \mathrm{kg})$ & 5880 \\
\hline 12. & Magnesium $(\mathrm{mg} / \mathrm{kg})$ & 984 \\
\hline
\end{tabular}

Table 2:-Morphological and Colony characterization of the J9 isolate from Jodia.

\begin{tabular}{|l|l|}
\hline Morphological and Colony characterization & J9 \\
\hline Gram Stain & Gram positive \\
\hline Shape & Rod \\
\hline Size & Medium \\
\hline Shape & Rhizoidal \\
\hline Margin & Undulate \\
\hline Elevation & Flat \\
\hline Texture & Rough \\
\hline Opacity & Translucent \\
\hline Consistency & Dry \\
\hline Pigmentation & Pale yellow \\
\hline
\end{tabular}



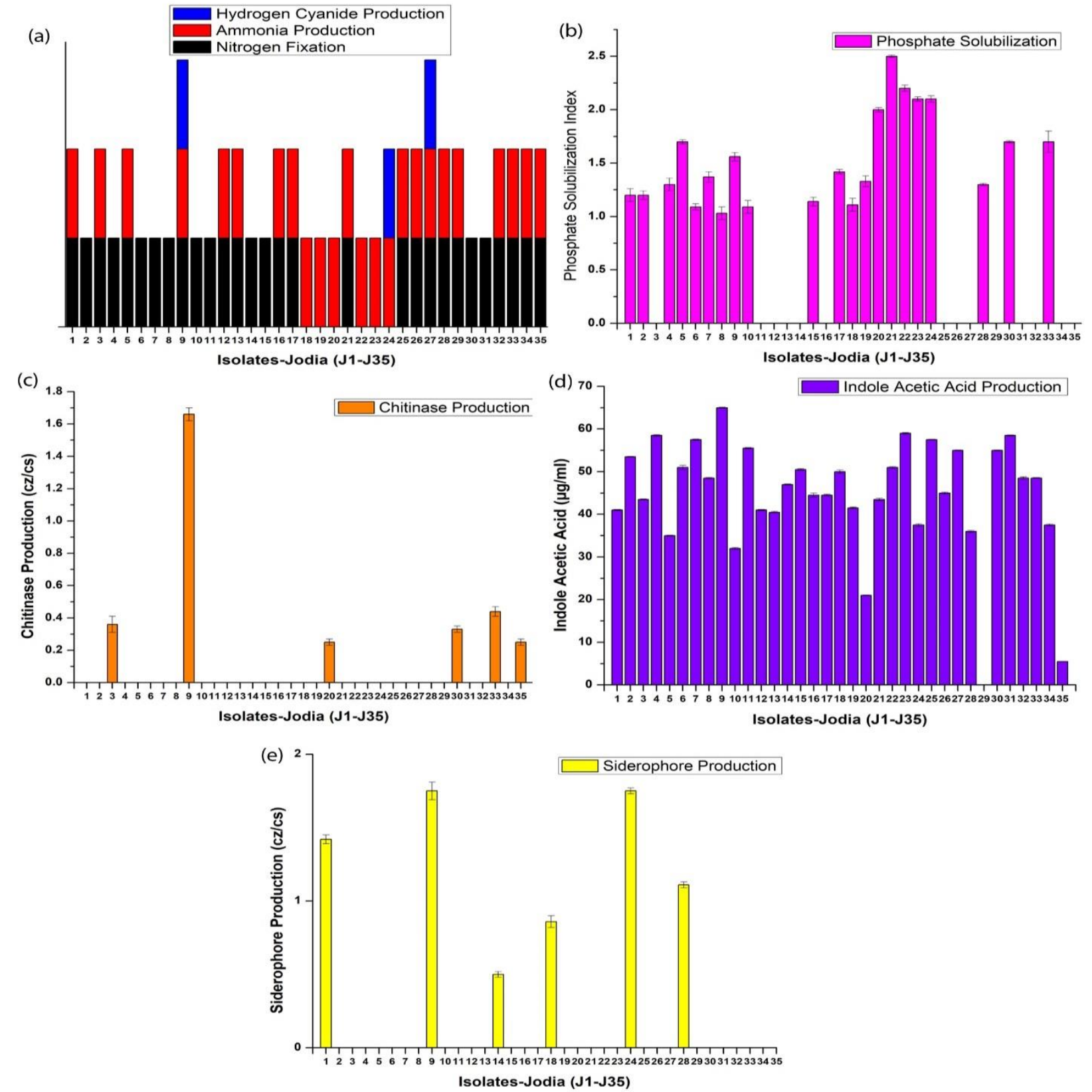

Figure 1:-Plant growth promoting traits of thirty five isolates (J1-J35) (a) hydrogen cyanide production, ammonia production and nitrogen fixation; (b) phosphate solubilization; (c) chitinase production; (d) indole acetic acid production and (e) siderophore production. 

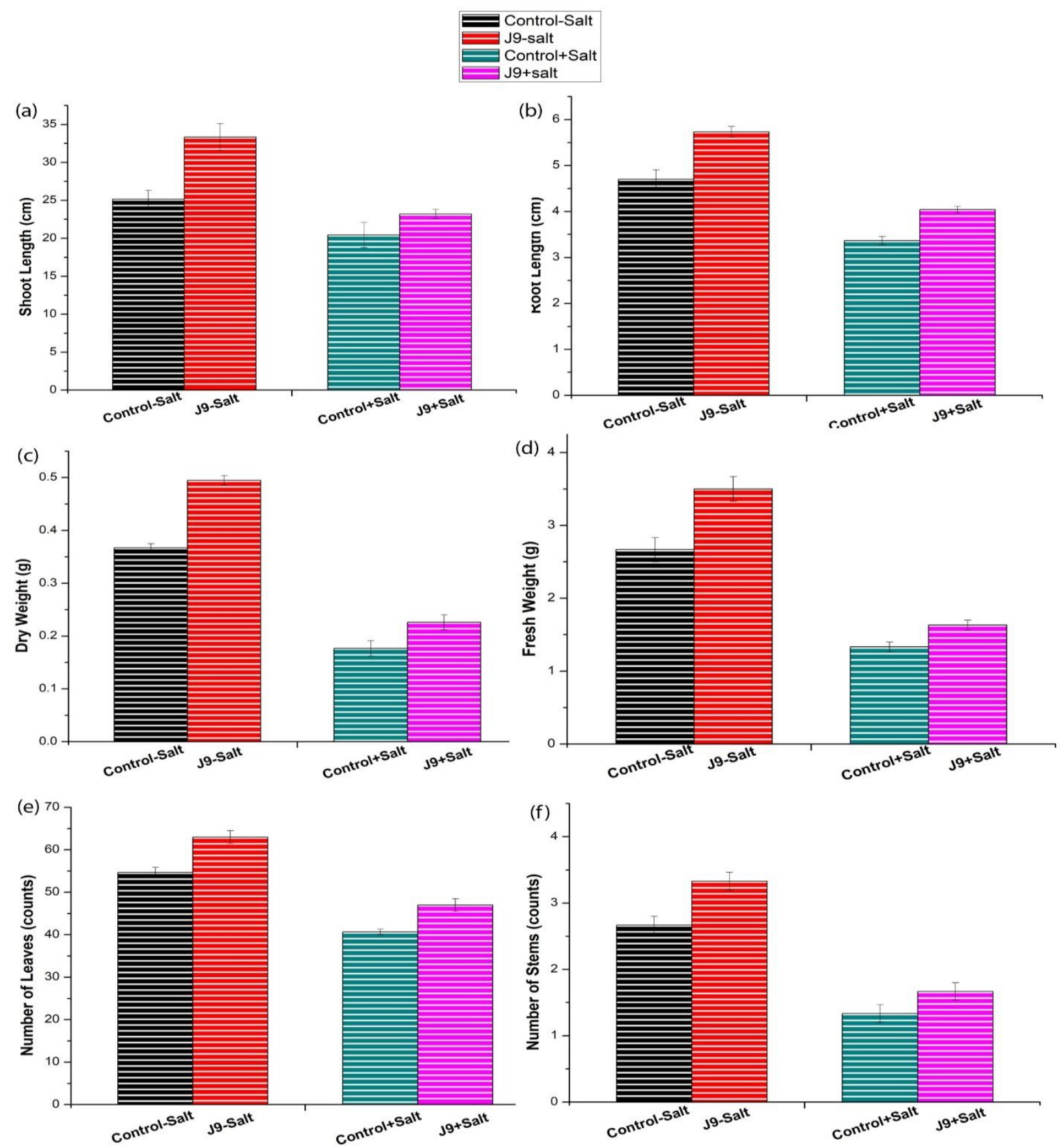

Figure 2:-The changes in the physical parameters of groundnut plant by $\mathrm{J} 9$ isolate in absence and presence of $\mathrm{NaCl}$ $(100 \mathrm{mM})$ salinity stress with reference to control.

\section{References:-}

1. Alström, S., \& Burns, R. G. (1989). Cyanide production by rhizobacteria as a possible mechanism of plant growth inhibition. Biology and Fertility of Soils, 7(3), 232-238.

2. Bar-Yosef, B., Rogers, R., Wolfram, J., \& Richman, E. (1999). Pseudomonas cepacia-mediated rock phosphate solubilization in kaolinite and montmorillonite suspensions. Soil Science Society of America Journal, 63(6), 1703-1708.

3. Bharti, N., Pandey, S. S., Barnawal, D., Patel, V. K., \& Kalra, A. (2016). Plant growth promoting rhizobacteria Dietzia natronolimnaea modulates the expression of stress responsive genes providing protection of wheat from salinity stress. Scientific reports, 6, 34768. 
4. Cappuccino, J. G., \& Sherman, N. (1996). Microbiology: a laboratory manual.

5. Garg, P. (2012). Energy scenario and vision 2020 in India. Journal of Sustainable Energy \& Environment, 3(1), 7-17.

6. Gordon, S. A., \& Weber, R. P. (1951). Colorimetric estimation of indoleacetic acid. Plant physiology, 26(1), 192.

7. Grattan, S., \& Grieve, C. (1992). Mineral element acquisition and growth response of plants grown in saline environments. Agriculture, ecosystems \& environment, 38(4), 275-300.

8. Groß, F., Durner, J., \& Gaupels, F. (2013). Nitric oxide, antioxidants and prooxidants in plant defence responses. Frontiers in plant science, 4, 419.

9. Ilangumaran, G., \& Smith, D. L. (2017). Plant growth promoting rhizobacteria in amelioration of salinity stress: a systems biology perspective. Frontiers in plant science, 8, 1768.

10. Majeed, A., Abbasi, M. K., Hameed, S., Imran, A., \& Rahim, N. (2015). Isolation and characterization of plant growth-promoting rhizobacteria from wheat rhizosphere and their effect on plant growth promotion. Frontiers in microbiology, 6, 198.

11. Martínez-Atienza, J., Jiang, X., Garciadeblas, B., Mendoza, I., Zhu, J.-K., Pardo, J. M., \& Quintero, F. J. (2007). Conservation of the salt overly sensitive pathway in rice. Plant physiology, 143(2), 1001-1012.

12. Mathivanan, S., Chidambaram, A., Sundramoorthy, P., Baskaran, L., \& Kalaikandhan, R. (2014). Effect of combined inoculations of Plant Growth Promoting Rhizobacteria (PGPR) on the growth and yield of groundnut (Arachis hypogaea L.). International Journal of Current Microbiology and Applied Sciences, 3(8), 1010-1020.

13. Pahari, A., \& Mishra, B. B. (2017). Antibiosis of siderophore producing bacterial isolates against phythopathogens and their effect on growth of okra. Int. J. Curr. Microbiol. App. Sci, 6(8), 1925-1929.

14. Pikovskaya, R. (1948). Mobilization of phosphorus in soil in connection with vital activity of some microbial species. Mikrobiologiya, 17, 362-370.

15. Piromyou, P., Buranabanyat, B., Tantasawat, P., Tittabutr, P., Boonkerd, N., \& Teaumroong, N. (2011). Effect of plant growth promoting rhizobacteria (PGPR) inoculation on microbial community structure in rhizosphere of forage corn cultivated in Thailand. European Journal of Soil Biology, 47(1), 44-54.

16. Savci, S. (2012). An agricultural pollutant: chemical fertilizer. International Journal of Environmental Science and Development, 3(1), 73.

17. Schwyn, B., \& Neilands, J. (1987). Universal chemical assay for the detection and determination of siderophores. Analytical biochemistry, 160(1), 47-56.

18. Shahbaz, M., \& Ashraf, M. (2013). Improving salinity tolerance in cereals. Critical reviews in plant sciences, 32(4), 237-249.

19. Sneath, P. H., Mair, N. S., Sharpe, M. E., \& Holt, J. G. (1986). Bergey's manual of systematic bacteriology. Volume 2: Williams \& Wilkins.

20. Yamaguchi, T., \& Blumwald, E. (2005). Developing salt-tolerant crop plants: challenges and opportunities. Trends in plant science, 10(12), 615-620. 